\title{
Enforcement and Network Capacity in Spectrum Sharing: Quantifying the Benefits of Different Enforcement Scenarios
}

\author{
Mohammed Altamimi Martin BH Weiss \\ School of Information Sciences \\ University of Pittsburgh \\ Pittsburgh PA 15260 \\ ( $\underline{\text { msa33@ } @ \text { pitt.edu }} ; \underline{\text { mbhw@pitt.edu) }}$
}

\section{$\underline{\text { Abstract }}$}

Recent studies have forecasted major growth in mobile broadband traffic. Due to the predicted high growth rate of mobile broadband traffic over the coming years (demand), there is a need for more wireless network capacity (supply). One of the major approaches to expand mobile wireless capacity is to add more spectrum to the market by enabling "spectrum sharing". The FCC has issued many reports indicating that the US is dangerously close to running out of capacity for mobile data, which is why the FCC and the NTIA have been working continually to enable spectrum sharing.

Spectrum sharing has moved from being a radical notion to a principal policy focus in the past decade. Enabling spectrum sharing regimes means that sharing agreements must be implemented. To have meaning, those agreements must be enforceable. The focus of this paper is to determine the relationship between enforcement methodologies and benefits of spectrum sharing through sharing between government and commercial users. Sharing between the government incumbents (i.e. Federal or non-Federal agencies) and commercial wireless broadband operators/users is one of the key forms of spectrum sharing that is recommended by the NTIA, the FCC, and the PCAST report. To address this problem, we build a model to quantitatively examine the relationships between different enforcement scenarios and sharing benefits. We model two case studies, 1695$1710 \mathrm{MHz}$ band and 3550-3650 MHz band. 


\subsection{Introduction}

The increasing demand for spectrum makes the introduction of more spectrally efficient technologies and management regimes essential. Recent evidence demonstrates that the demand for spectrum access rights exceeds the available supply [1][2][3]. One of the main factors leading to this imbalance is that the spectrum is not as well utilized as it could be. The future of wireless necessitates that we use the spectrum resources more efficiently, which requires a transition to a future in which spectrum is shared more intensively.

The growing demand pressure expanded access to legacy networks for new uses and the need for significant spectrum reform to enable such sharing has been noted by the Federal Communications Commission (FCC) Spectrum Policy Task Force, reaffirmed by the National Broadband Plan (NBP) and the President's call for an additional 500MHz of spectrum for mobile broadband [3] [1]. Most recently, the President's Council of Advisors on Science and Technology (PCAST) report address this issue intensively [4]. In addition, the National Telecommunications and Information Administration (NTIA) has proposed several bands to facilitate spectrum sharing between different level of users such as Primary Users (PUs) and Secondary Users (SUs) [5].

It is clear that mobile broadband is the great infrastructure challenge for wireless operators, particularly with the existence of several evidences of significant increase in mobile broadband traffic [4]. Data usage over mobile networks is rapidly increasing as more users surf the web, check email, and watch video on smart phones/tablets. Several research analysts share the view that mobile broadband traffic will continue a significant upward trend over the next 5-10 years [1] [6] [7].

The focus of this work is to determine the relationship between enforcement methodologies and additional benefits of spectrum sharing through sharing between government and commercial users. Sharing between the government incumbents (i.e. Federal or non-Federal agencies) and commercial wireless broadband operators/users is one of the key forms of spectrum sharing that is recommended by the NTIA, the FCC, and the PCAST report. There are many scenarios where spectrum sharing can take place, so the emphasis of the paper is on government and commercial spectrum sharing. The government incumbent will be the PUs; on the other hand, the commercial users be the SUs. 
Implementing spectrum sharing regimes on a non-opportunistic basis means that sharing agreements must be implemented. To have meaning, those agreements must be enforceable. This paper will try to do reasoning about enforcement of spectrum sharing and will demonstrate and examine diverse scenarios, which can be implemented, at different spectrum sharing environments. We model two case studies, 1695-1710 MHz band and 3550-3650 MHz band. For more information about the PUs and expected SUs of these two bands, please refer to previous work [8] [9].

\subsection{Enforcement and Spectrum sharing}

The ultimate goal of enforcement is to induce "socially optimal" behavior, which may deviate from "individually optimal" behavior because of externalities, mistakes, or other sources of market failures. Socially optimal behavior includes investments in protection (harm avoidance) technology and in operating behavior that results in socially desirable outcomes. The full consideration of what an appropriate definition of harmful interference is beyond the scope of this work. For further discussion about harmful interference, please refer to [10], [11].

Traditionally, in the spectrum field, the enforcement process is to prevent an interference event before it happens, such as geographical or spectral (i.e. guard band) separation between licensees, and transmitters/receivers specifications [12]. There are two loci at which usage rights may be enforced:

- Ex ante enforcement: The actions that been taken to prevent and avoid any potentially harmful interference event before it has occurred.

- Ex post enforcement: The actions that been taken after a potentially harmful interference event has occurred.

Ex ante and ex post approaches work in tandem, not in isolation. Thus, the choice of ex ante approach affects ex post strategies [12]. The choice of how to design the enforcement mechanism directly and indirectly impacts the design and costs of usage rights enforcement. In particular, the costs of inducing good behaviors (avoiding bad ones) must be balanced against the social costs and benefits under different scenarios. Therefore, the cost of strong ex ante rules is that they need to be enforceable and may pose the risk of overly restricting behaviors that may be reduce the 
welfare enhancing (e.g., innovation) as well as decreasing the value of the sharing opportunity for the entrant (i.e., SUs).

This paper evaluates the benefits of enforcement. In other word, it sets the upper bound of the reasonable cost of enforcement to share the spectrum in specific scenarios. We evaluate the shared area by moving from pure ex ante enforcement settings toward ex post enforcement settings in our model.

The review of literature shows the critical need to add more wireless network capacity. There are three factors to overcome this capacity crunch: (1) adding more cell sites, (2) technology, and (3) adding more spectrum [7] [13]. The focus will be on spectrum sharing as part of the third factor, which can be considered as adding more spectrum liquidity to the wireless market.

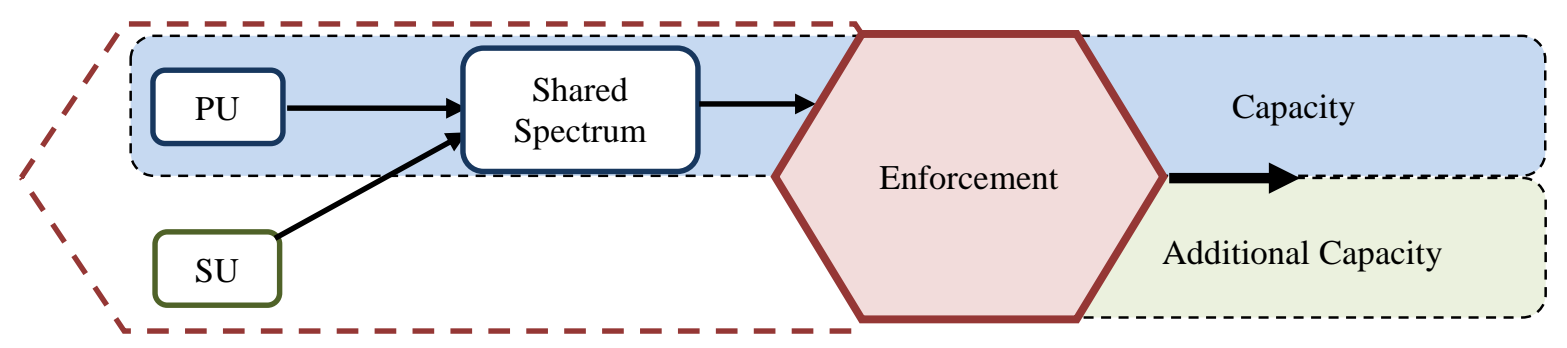

Figure 2-1 Illistration of enforcemnts effect on spectrum sharing 


\subsection{Spectrum Sharing Model}

The current approach to spectrum sharing using exclusion zones (as suggested by NTIA) is based primarily on ex ante enforcement by setting a very large exclusion zones. The proposed modeling of geographical exclusion zones moves from a purely ex ante approach (large exclusion zone only) towards ex post enforcement, see Figure 3-1. The model includes these additions:

- Evaluation the benefits of spectrum sharing within the exclusion zone.

○ Model of a "Gray space" area.

○ Model of a "Black space" area.

- Evaluation the benefits of spectrum sharing outside the exclusion zone.

○ Model of a "White space" area.

\subsection{Main Idea}

In Figure 3-1, the PU antenna is represented in the center of simulated area/circle. The X-axis represents the distance from the PU antenna to the perimeter of the "PU usage right area".

$>\mathrm{R}_{1}$ : proposed radius of Back space.

$>\mathrm{R}_{2}$ : proposed radius of Gray space areas. $\mathrm{R}_{1}$ and $\mathrm{R}_{2}$ are the key variables affecting the function of sharing utilization.

$\mathrm{R}_{3}$ : the radius of PU usage right area. It is the total area where the PU is originally licensed to use the spectrum. For simplicity propose, we set this radius to be $100 \mathrm{~km}$ during the simulation. 
Figure 3-1 Model Summary

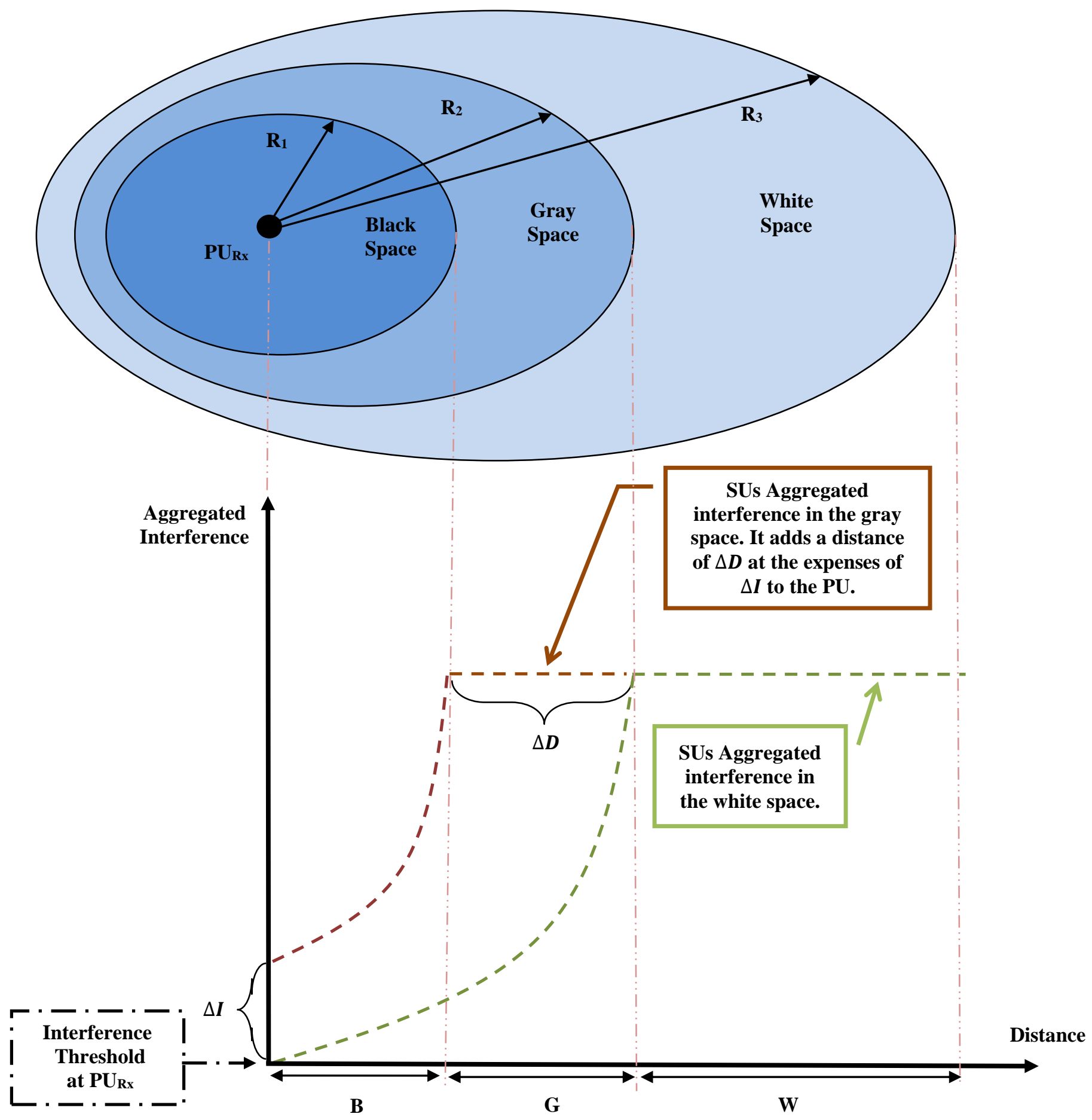




\subsubsection{White Space $(W)$ :}

- $\quad$ Area $=\pi\left(R_{3}^{2}-R_{2}^{2}\right)$

- This is the area where the SUs can operate at the maximum standardized power-limit without causing any interference to the PU.

- A smaller enforcement effort is needed to facilitate sharing in this area compared to the other proposed areas.

- In special cases where the cost of ex post enforcement is higher than the benefits of sharing $\mathrm{G}$ and $\mathrm{B}$ spaces, we probably need ex ante enforcement only, through simple database holding the boundary of the exclusion zone at $\mathrm{R}_{2}$.

- The relatively low enforcement effort in $\mathrm{W}$ space area is one of the major advantages of sharing, where utilization increases at lower enforcement cost compared to other areas.

- $\mathrm{R}_{3}$ represents either the border of "spectrum usage right" of the PU or it could be bounded by another exclusion zone domain.

- It is very important to differentiate between "operations area" and "usage right area".

- The usage right area is the geographical area where the PU is licensed to use its spectrum/frequency.

- The operations area is the geographical location where the PU uses the spectrum (i.e., builds its network).

\subsubsection{Gray Space (G):}

- $\quad$ Area $=\pi\left(R_{2}^{2}-R_{1}^{2}\right)$ 
- This is the area where the aggregated interference from SUs will be greater than the noise floor of the PU receivers and below the maximum interference threshold set by the PU which is part of sharing enforcement procedure.

- $\mathrm{R}_{1}$ depends on the sensitivity of PU receivers to additive noise caused by spectrum sharing.

\subsubsection{Black Space (B):}

- $\operatorname{Area}=\pi\left(R_{1}^{2}\right)$

- This area is close to the PU receiver, where the penalties for interference would be set to give the $\mathrm{SU}$ an incentive to create profit maximizing zones out from sharing.

- Sharing in this area is expected to be heavily based on ex post enforcement.

- B space is expected to be shared by a centralized SU, represented, for example, by a single operator or interface that would manage all the related secondaries. This is the most likely case when we have large cells of SUs. Thus, enforcing SU behavior will be achieved through this single interface. For more information about the differences between centralized and decentralized enforcement, please refer to [12] [9].

- In special cases, the black space could be very small or almost zero, in which case the PU can coexist with the maximum possible interference threshold caused by SUs (where the whole exclusion zone becomes $\mathrm{G}$ space).

- One of the purposes of this model is to evaluate the benefits of $\mathrm{W}, \mathrm{G}$, and B spaces, even if it is not possible to share the G and/or B spaces. In the end, we need the value of the exclusion zone for each level of enforcement scenario, so that, for example, we could recommend re-locating the PU antenna if possible based on a cost-benefit analysis. 


\subsection{Simulation Main Function}

The key component of this simulation is the methodology that has been used to determine the aggregated interference level at a PU location with many SUs sharing the band. In this paper, we have created a reasonable representation of the aggregate interference in the spectrum sharing environment where multiple SUs cause interference to a single PU. Moreover, we will explore the impact of aggregate interference over sharing utilization.

In this model, each SU can cause interference to the PU which can be defined in equation (1). Then, aggregated interference is calculated by converting the individual interference in " $\mathrm{dBm}$ " to "Watt" in order to add them together. Then the sum is converted to "dBm" again in equation (2).

$$
\begin{aligned}
& I=I_{S U}+G_{P U}+G_{S U}-P L-F D R-L_{P U}-L_{\text {Additional }} \\
& I_{A G G}=10 \log _{10}\left[\sum_{j=1}^{N} I\right]+30
\end{aligned}
$$

Table 3-1 Equations (1) and (2) description.

\begin{tabular}{|c|c|c|}
\hline & Description & Unit \\
\hline I & SU's power (interference) at the PU receiver & $\mathrm{dBm}$ \\
\hline ISU & SU transmitted power & $\mathrm{dBm}$ \\
\hline GPU & Antenna gain of the PU & $\mathrm{dBi}$ \\
\hline Gsu & Antenna gain of the SU & $\mathrm{dBi}$ \\
\hline PL & Propagation Loss & $\mathrm{dB}$ \\
\hline FDR & Frequency Dependent Rejection & $\mathrm{dB}$ \\
\hline LPU & Losses at PU antenna & $\mathrm{dB}$ \\
\hline LAdditional & Additional Losses (e.g. indoor factor) & $\mathrm{dB}$ \\
\hline I $_{\mathbf{A G G}}$ & Aggregated interference at PU receiver & $\mathrm{dBm}$ \\
\hline $\mathbf{N}$ & Number of SUs & $\mathrm{N}$ \\
\hline
\end{tabular}


Since the number of simulated SUs is very large (i.e., tens of thousands) around the PU location, the transmitted power should be modeled in a more accurate way. To do this, we follow a probability distribution function for the transmitted power of SUs.

The gain of SU antennas is set at zero in this model, which means that we are not considering any gain on the SU side due to the characteristics of the technology representing the SUs, such as LTE-UE, Femtocells, and WiFi. For the PU, we follow the ITU-R F.1245-1 recommendation [14]. Figure 3-2 shows the azimuth and elevation antenna pattern from the simulation model when maximum antenna gain equals $43 \mathrm{dBi}$ and the minimum elevation angle for PU antenna is 27 degrees.

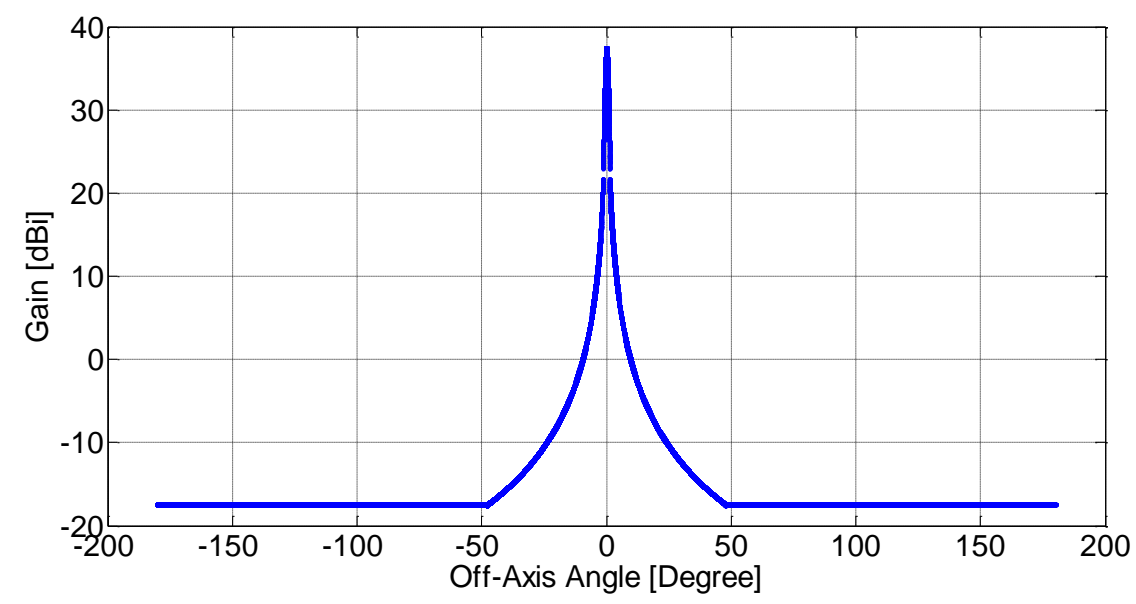

Figure 3-2 PU antenna gain pattern

Per the ITU ${ }^{1}$ and NTIA documents [15], "Frequency Dependent Rejection (FDR) accounts for the fact that not all of the undesired transmitter energy at the receiver input will be available at the detector. FDR is a calculation of the amount of undesired transmitter energy that is rejected by a victim receiver". Although FDR is has been built into the simulator, in this paper, we ignore its effects in both $1.7 \mathrm{GHz}$ and $3.5 \mathrm{GHz}$ cases to simplify the exposition.

\footnotetext{
${ }^{1}$ See, Recommendation ITU-R SM.337 (2008).
} 


\subsection{Model Design and Findings}

The PU is assumed to be a single PU receiver and there are a large number of SUs. In the case of spectrum sharing, the SUs will be seen by the PU as additive noise/interference on top of any pre-existing noise (i.e., noise before sharing). This additive interference will affect PU receivers only, not the transmitters. Therefore, the location of the PU receivers is what we are considering to force a protection distance between SUs' location and PU receivers.

\subsubsection{Settings}

- A single PU receiver that is bounded by three types of zones: $\mathrm{W}, \mathrm{G}$ and $\mathrm{B}$ spaces.

- The external radius (i.e., simulation area) is $100 \mathrm{~km}$.

- We will assume the noise floor level of the PU is $\mathrm{G}_{\mathrm{boundary}}$.

- It is assumed that the PU will agree to tolerate some extra interference (i.e., $\Delta I$ ) to increase the sharing utilization (i.e., $\Delta D$ ). This extra interference level is bounded by B boundary.

- $G_{\text {boundary }}$ and $B_{\text {boundary }}$ are negative values $\quad[\mathrm{dBm}]$

○ $G_{\text {boundary }}<B_{\text {boundary }}$ or $\left|G_{\text {boundary }}\right|>\left|B_{\text {boundary }}\right|$

- From these distances, we can find out the additive area that can be added to the sharing scenario.

\subsubsection{Research Assumptions}

In this paper, certain assumptions are taken into consideration:

- There are two types of spectrum sharing: opportunistic or non-opportunistic sharing. We consider non-opportunistic sharing, where there is an agreement (i.e., coordination) between PUs and SUs to make the sharing possible. 
- We assume that the PU is a government incumbent (i.e. Federal or non-Federal agency) and that the SU is a commercial wireless broadband operator/user.

- There are two types of in-band interference that may exist due to the sharing scenario illustrated in this paper :

- Interference from a SU to a PU:

- This is the interference under consideration in this work, where the PU should be protected.

- This interference will be mitigated by ex ante and ex post enforcement.

- Interference from a PU to a SU:

- This type of interference is caused by the PU signal reaching the operation area of SUs.

- The exclusion zone will be modeled to protect the PU only.

- This type of interference is beyond the scope of this work, where the SUs should, typically, expect this type of interference as part of the sharing environment.

\subsubsection{Area of simulation}

The simulated area is a circle of $100 \mathrm{~km}$ radius where the PU receiver is centered in the middle. Since $100 \mathrm{~km}$ is a long distance, the model is capable of dividing it into different segments, each with its own terrain and population characteristics. For simplicity's sake, we divide it into two segments:

- Inner area: the area is relatively small in order to capture the terrain characteristics of the most interferer area to the PU. For example, Figure 3-3 shows that the inner area has a radius of $40 \mathrm{~km}$. 
- Outer area: the area between the inner area radius and $100 \mathrm{~km}$. SUs in this area have less effect on the PU receiver compared to SUs in the inner area.

The SUs are randomly distributed over the simulated area. The key input to the model is the density of population per $\mathrm{km}^{2}$ to represent the existence of SUs. Not all the population of that area transmit at the same time, so, we multiply the population density by what we call the "Active Factor", which can vary based on the of simulated SU technology type.

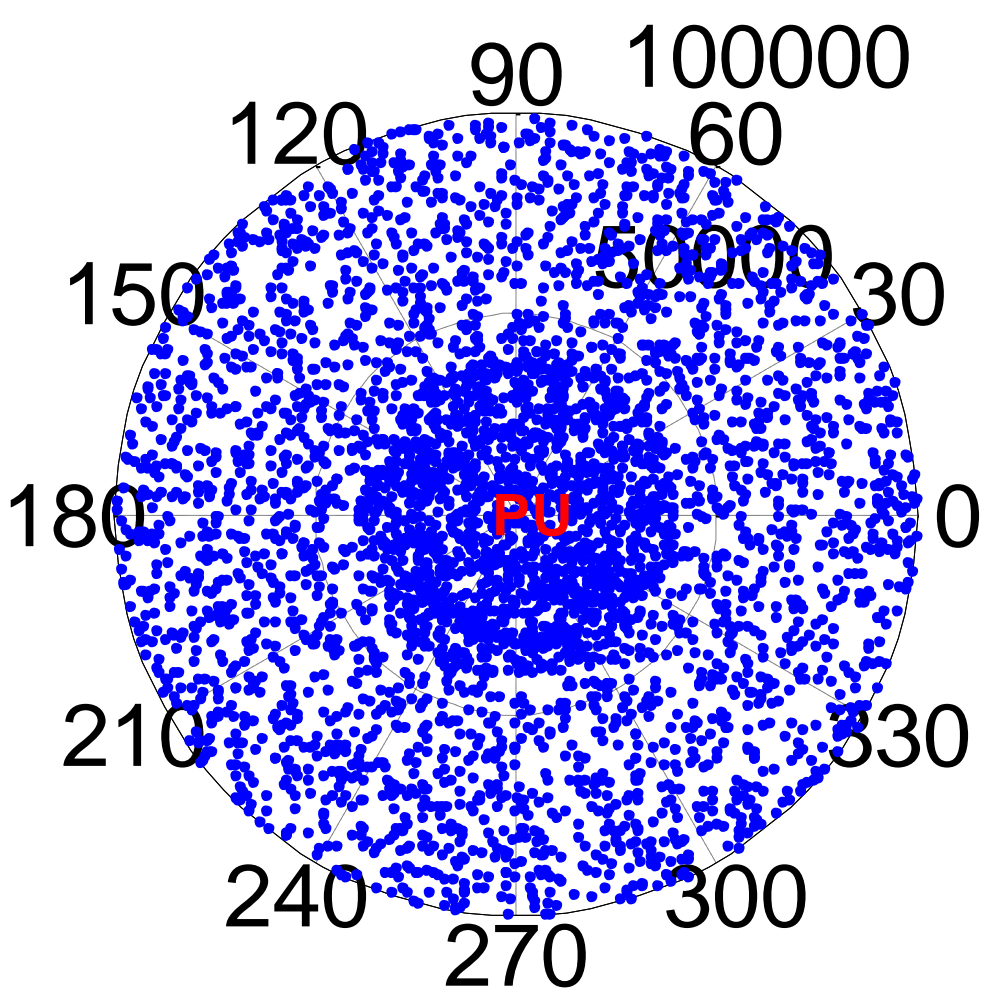

Figure 3-3 Area of simulation. The PU receiver is located in the center. 


\subsubsection{Findings}

In this section, we will examine the main inputs and variables in this model; the rest will be covered through the real case scenarios that follow in the next sections. The major inputs to this model analysis are listed in Table 3-2.

Table 3-2 Major model inputs used in this section

\begin{tabular}{|c|c|c|}
\hline \multicolumn{2}{|c|}{ Frequency } & $2 \mathrm{GHz}$ \\
\hline \multicolumn{2}{|c|}{ "PU Antenna" azimuth angle } & 360 Degree \\
\hline \multicolumn{2}{|c|}{ Minimum "PU Antenna" elevation angle } & 20 Degree $^{2}$ \\
\hline \multicolumn{2}{|c|}{ SU transmitted power $\left(\mathrm{I}_{\mathrm{SU}}\right)$} & Standard LTE-UE \\
\hline \multicolumn{2}{|c|}{ Maximum "PU Antenna" gain } & $40 \mathrm{dBi}$ \\
\hline \multicolumn{2}{|c|}{ SU gain $\left(\mathrm{G}_{\mathrm{SU}}\right)$} & $0 \mathrm{dBi}$ \\
\hline \multicolumn{2}{|c|}{ Additional Losses (L Additional $_{\text {) }}$} & $0 \mathrm{~dB}$ \\
\hline \multicolumn{2}{|c|}{ FDR } & $0 \mathrm{~dB}$ \\
\hline \multicolumn{2}{|c|}{$\mathrm{L}_{\mathrm{PU}}$} & $2 \mathrm{~dB}$ \\
\hline \multirow{2}{*}{ Inner area } & Radius & From 0 to $40 \mathrm{~km}$ \\
\hline & Density & 6 Active SUs per $\mathrm{km}^{2}$ \\
\hline \multirow{2}{*}{ Outer area } & Radius & From $40 \mathrm{~km}$ to $100 \mathrm{~km}$ \\
\hline & Density & 2 Active SUs per $\mathrm{km}^{2}$ \\
\hline \multicolumn{2}{|c|}{ G boundary } & $-110 \mathrm{dBm}$ \\
\hline \multicolumn{2}{|c|}{ B boundary } & $-90 \mathrm{dBm}$ \\
\hline
\end{tabular}

Note:

If one/number of these inputs mentioned in the $\mathrm{x}$-axis or in the legend of the following figures, that means they take the values mentioned in such figures. The rest stay as they are listed in this table.

${ }^{2}$ The minimum elevation angle is consider as fixed input and added to the "gain function" in the simulation model; that because we try to represent the worst case scenario which is the case where the interference increase as we decrease the elevation angle. 


\subsubsection{SUs Density}

This section examines the relationship between the level of SU density and the radius of different types of exclusion zones. W space radius is fixed at $100 \mathrm{~km}$ and is constant thought out the simulation. G and B space radiuses vary based on SU density. Figure 3-4 summarize these relationships.

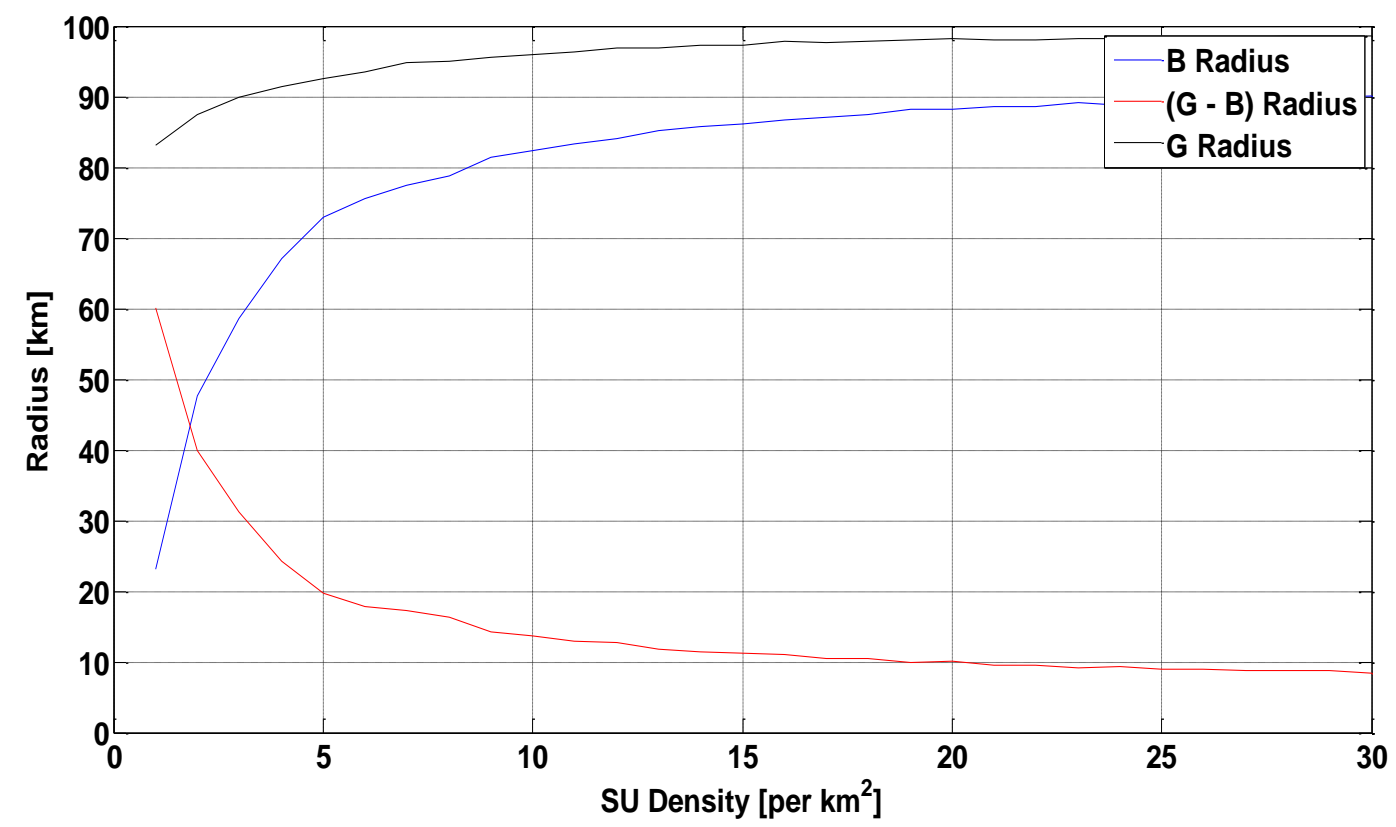

Figure 3-4 Relationship between SU density and Black and Gray radiuses.

By examining the above figure, we can conclude the following about this model setting:

- Interestingly, the $\mathrm{G}$ radius is almost the same the for any SU density greater than 6 users per $\mathrm{km}^{2}$.

- This suggest that the $\mathrm{W}$ space is not sensitive to SU density above 6 users per $\mathrm{km}^{2}$.

- Due to the difference in $\mathrm{G}$ and $\mathrm{B}$ boundaries (in $\mathrm{dBm}$ ), it is obvious that $\mathrm{B}$ radius is more sensitive to density compared to $\mathrm{G}$ radius. 


\subsubsection{Frequency}

In this section, we will try to see how the simulated model reacts to different frequency bands. The frequency will vary from $0.5 \mathrm{GHz}$ to $5 \mathrm{GHz}$. The major variable is still the same as in Table 3-2, where the frequency is the variable. From Figure 3-5, and Figure 3-6, we can conclude the following:

- The effect of SU density decreases as we lower the frequency in a sharing environment. We can see that $\mathrm{G}$ radius has less variance at $0.5 \mathrm{GHz}$ compared to 5 $\mathrm{GHz}$, by moving along the $\mathrm{x}$-axis. This is also the case in $\mathrm{B}$ radius.

- At higher SUs density, the differences between the B radius (for example) at different frequencies is minimized.

- Frequency effect on B radius is minimal for $\mathrm{SU}_{\text {density }}>10 / \mathrm{km}^{2}$

- For example, if a regulator wants to assign two different SUs service with two different expected densities of SUs, all else being equal, then the service with less SUs density should be assigned to a higher frequency, and the other to a lower frequency. 


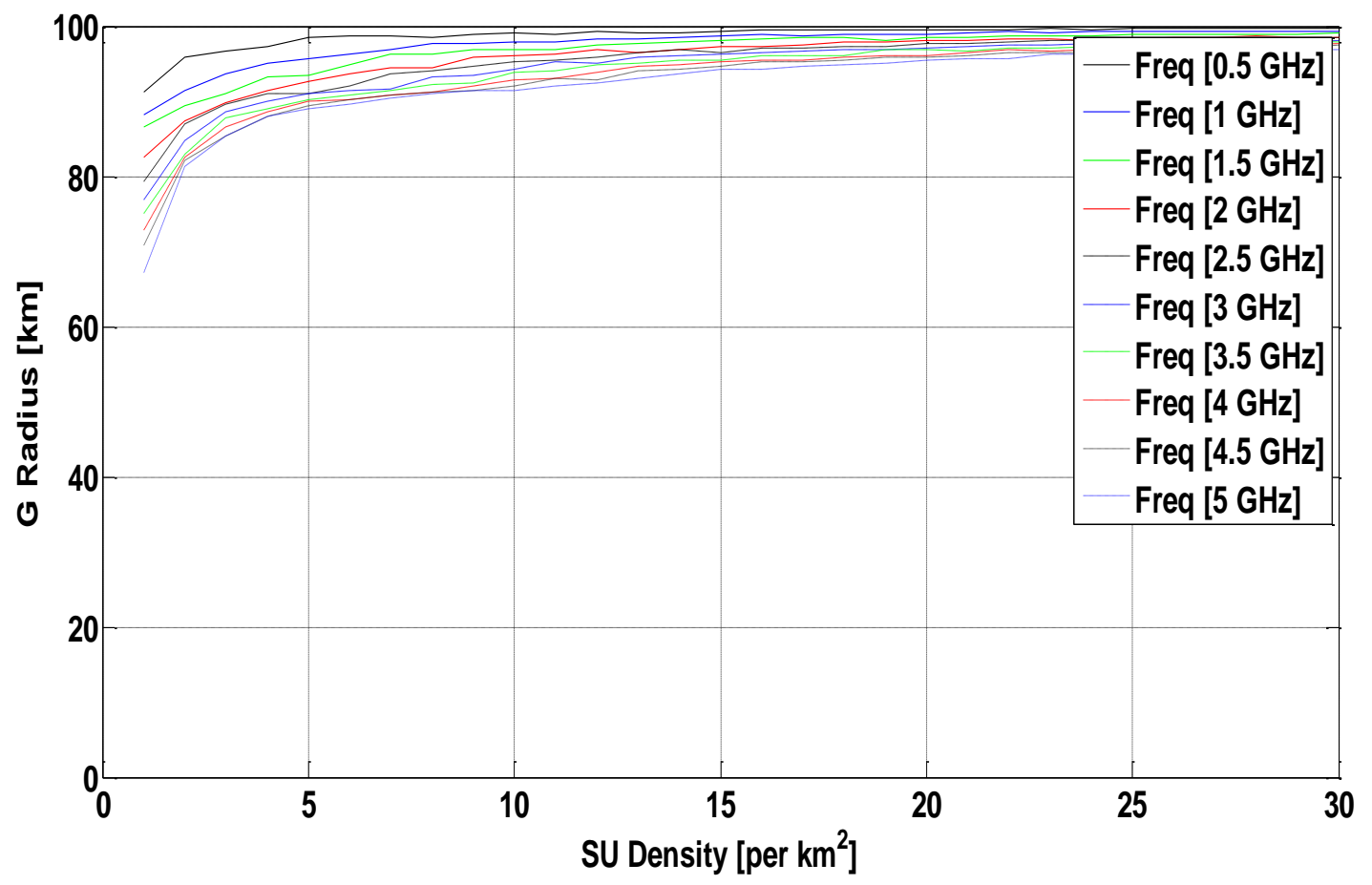

Figure 3-5 Illustration of frequency band effect on $\mathrm{G}$ radius. $\mathrm{SU} / \mathrm{km}^{2}$ is between 1 and 30 .

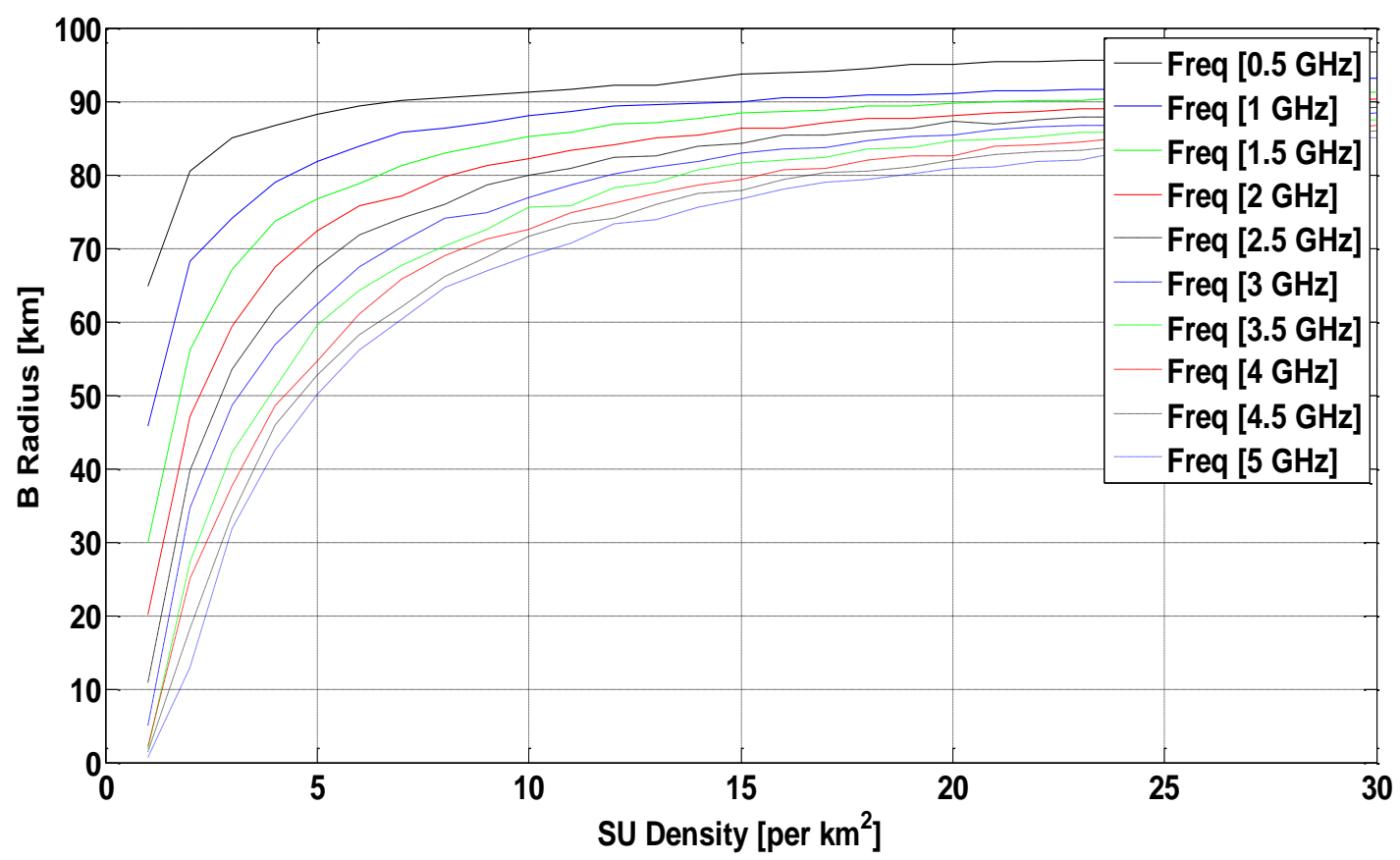

Figure 3-6 Illustration of frequency band effect on $B$ radius. $\mathrm{SU} / \mathrm{km}^{2}$ is between 1 and 30 


\subsubsection{Interference Threshold}

Here, we examine the effect of changing the interference threshold boundary (in $\mathrm{dBm}$ ) on the exclusion zone radius. To do that, we will consider one interference threshold in this simulation. We pick the $G$ boundary to examine this relationship over two different entries: (1) changing the SUs density, and (2) changing the frequency bands.

In Figure 3-7, the G radius remains at approximately $100 \mathrm{~km}$ till reaching $-130 \mathrm{dBm}$, for all different SUs density. Also, the G radius reaches zero around -70dBm. That leads to these findings:

- If the PU antenna noise floor is less than $(-130 \mathrm{dBm})$, it is very sensitive to interference, and the exclusion zones will be very large.

- If the noise floor is higher than $(-80 \mathrm{dBm})$, this means we will not need any exclusion zones at this model setting at SUs density less than or equal to 1 . This means, there is no $\mathrm{G}$ space in the case.

In Figure 3-8, the inner area density is $6 \mathrm{SUs} / \mathrm{km}^{2}$ and the outer area density is $2 \mathrm{SUs} / \mathrm{km}^{2}$. We can conclude the followings:

- At any specific point on the $\mathrm{G}$ boundary (x-axis), as the frequency decreases, the $\mathrm{G}$ radius increases.

- The sensitivity of the interference threshold is lower at higher SUs densities. That is clear from this figure, where the slope of the curves above radius $=40 \mathrm{~km}$ is higher (in magnitude) than below it.

- The bending on the curves at radius $=40 \mathrm{~km}$ is due to the different SUs densities between inner and outer areas. 


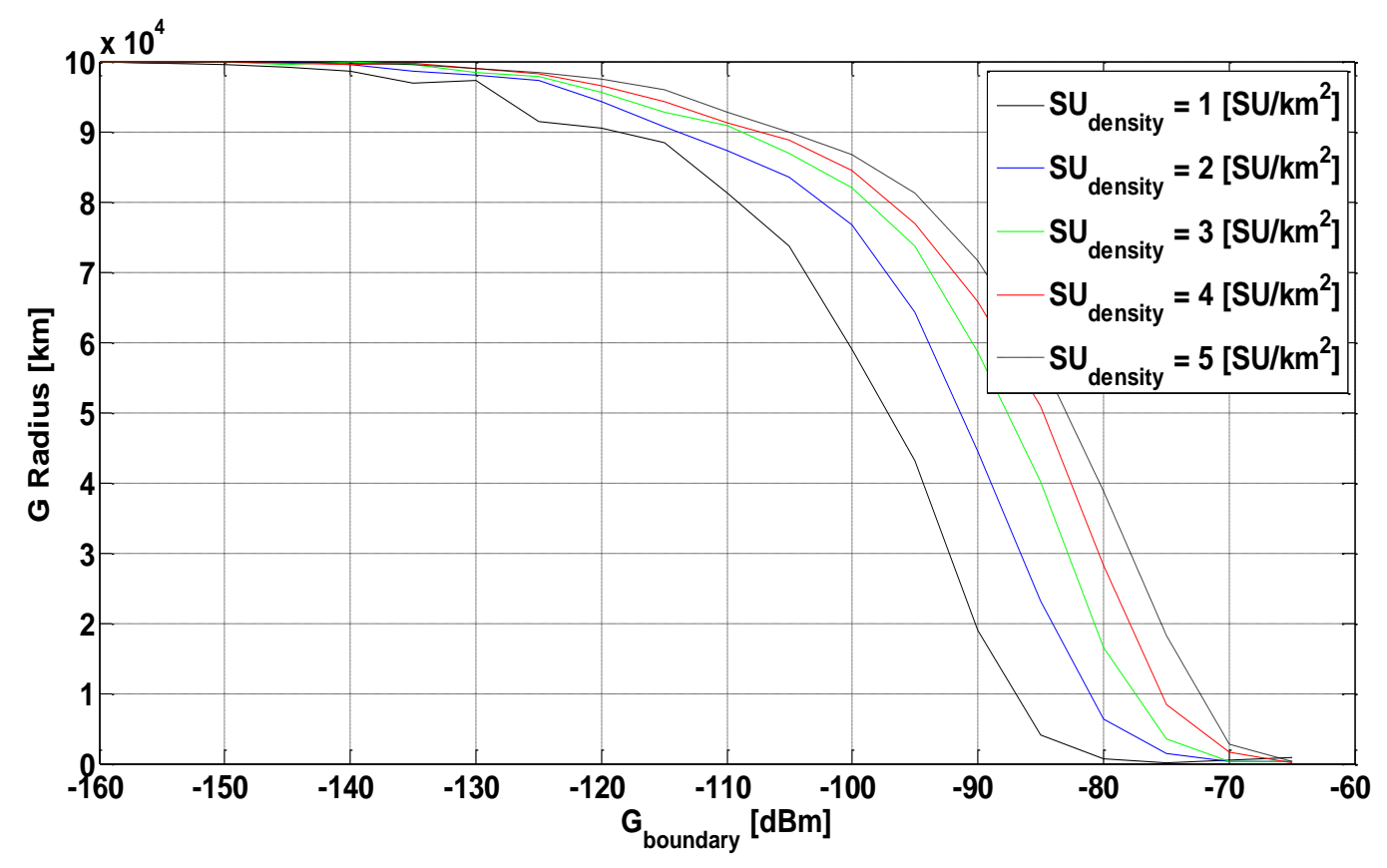

Figure 3-7 Effects of interference threshold on G radius over five different SUs densities.

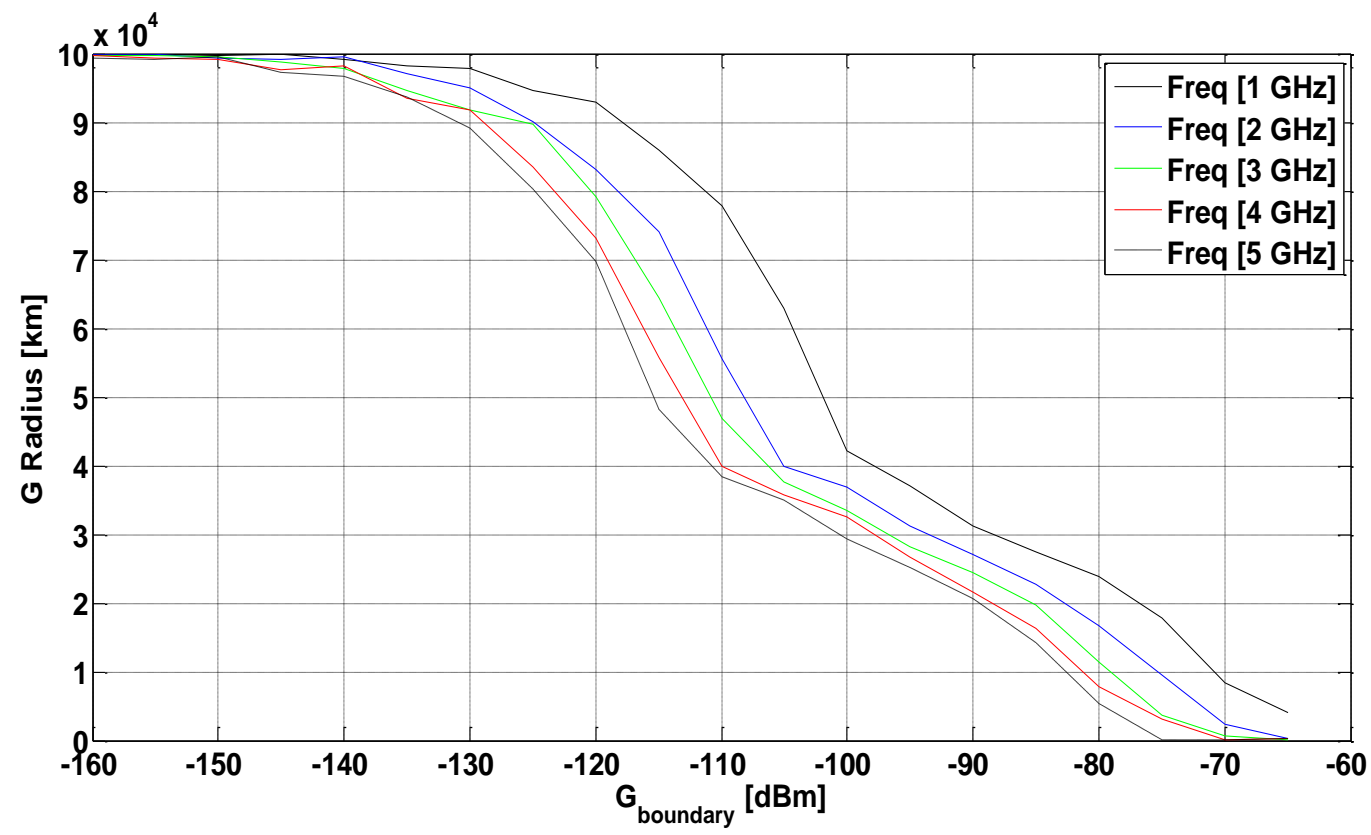

Figure 3-8 Effects of interference threshold on $G$ radius over five different frequency bands. 


\subsection{Case Studies of Government-Commercial Sharing}

\subsection{Spectrum Sharing in $1.7 \mathrm{GHz}$ band}

The $1695-1710 \mathrm{MHz}$ frequency range $(15 \mathrm{MHz})$ is allocated to Meteorological-Satellite (MetSat; space-to-earth) and meteorological aids (MetAids; radiosondes) services. According to the Commerce Spectrum Management Advisory Committee (CSMAC) report [15], sharing in the 1695-1710 MHz band should be limited to commercial systems operations (LTE mobile uplink use only). That is because, in part, the $1695-1710 \mathrm{MHz}$ is immediately adjacent to the AWS-1 uplink band (which will maximize its usefulness for commercial services) and because mobile uplinks transmit at much lower power than downlinks. Please refer to [9] and [8] for more information about the PU and $\mathrm{SU}$ in this proposed band for sharing.

\subsubsection{Simulation Setting}

The published information about MetSat earth-stations (by NTIA) is only for the original 18 earth stations. Therefore, we will illustrate our simulation methodologies using these 18 MetSat stations and that could be generalized to any additional stations.

The specifications of the 18 earth-stations are summarized in Appendix A (Table A1). Some of them are located in very populated areas. Therefore, part of our analysis is to find out which of these earth-stations should be re-located to increase the benefits of spectrum sharing.

The major additional factor that has been added to this analysis is the real population affected by the exclusion zone of each MetSat earth-station. To do that, a full analysis was performed at each earth-station to determine the population surrounding the earth-station. Appendix A (Table A2) summarizes these details. Some of the stations exist beside the coast line or on an island. Thus, we used the level of "zip-code area" to determine the population density to increase the accuracy of our analysis.

There are many advantages of doing population density analysis. First, we try to avoid assumption of the population density around each station. That allows us to determine a more exact cost/value of exclusion zones. Second, it gives us the ability to more accurately predict the number of "active SUs" in each sharing scenario. Also, we use this information to determine the type of 
path loss to use around each station based on the population density (e.g. open, suburban, small city, or large city).

These population analyses provide a powerful tool to evaluate the "opportunity cost" of B, G and W space areas. Figure 4-1 shows the population density for all 18 earth-stations based on the five different areas. One of the highest impacted area is the Miami earth-station, where there are 1.8 million people living within a $20 \mathrm{~km}$ radius of the earth-station.

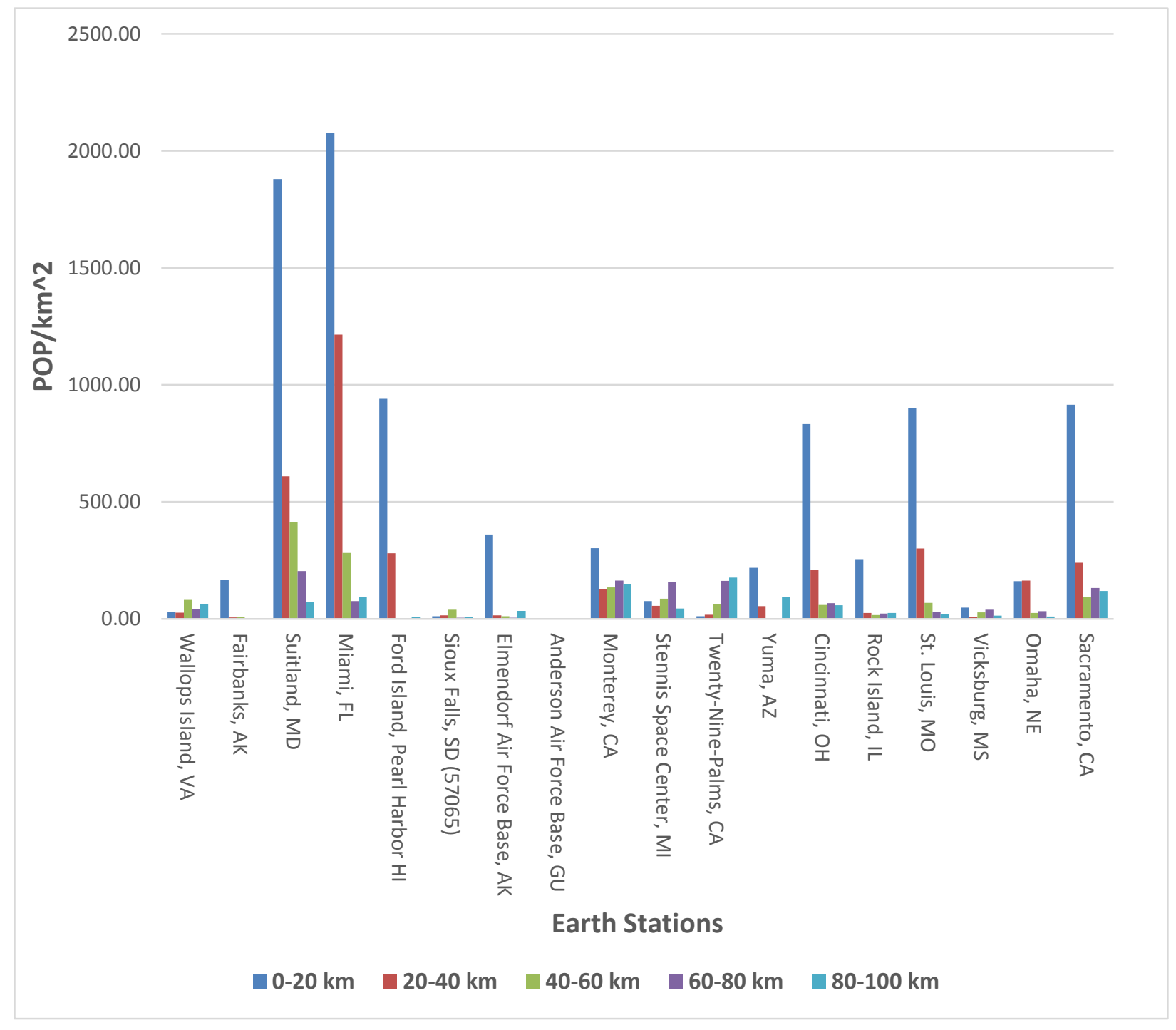

Figure 4-1 Population density for all 18 earth-station based on the five different areas. 
One of the most critical settings in simulation models is the $\mathrm{G}$ and $\mathrm{B}$ space boundaries (in $\mathrm{dBm})$, which defines each specific boundary. They are defined in MetSat as follows:

- Goundary

○ This is the "interference protection threshold" 3 at the PU antenna specification.

- In the MetSat case, it is in the range of $-120 \mathrm{dBm}$. Appendix A lists the interference protection threshold at each earth-station.

- B Boundary

- This is a new approach to be used to define B space area.

O It's value is $(+20 \mathrm{dBm})$ over G space boundary.

$\circ$ For example, if $\mathrm{G}_{\text {boundary }}=-122 \mathrm{dBm}$, then $\mathrm{B}_{\text {boundary }}=-102 \mathrm{dBm}$.

- As mentioned earlier, the PU is assumed to accept additional aggregated interference to its noise floor threshold as part of sharing enforcement procedure.

\subsubsection{Spectrum Sharing Benefits Evaluation}

To show the benefits of enforcement scenarios, we get the real cost of spectrum from the FCC auction-database of comparable spectrum bands. The most relevant and reasonable band to $1.7 \mathrm{GHz}$ is the AWS-1 band. This band was auctioned in 2006.

The following tables summarize our analysis for each earth-station. Table 4-1 shows the average $\$ / \mathrm{MHz}-\mathrm{POP}$ for each one of the stations, which is being used as input to evaluate the spectrum sharing benefits in our model. ${ }^{3}$ In this
interchangeably. 
We quantify the spectrum sharing benefits in MetSat case. First, the model will deliver the B and $\mathrm{G}$ radiuses as exclusion zones around each earth-station. Then, we can evaluate the additive gain of the additional proposed areas shared as B, G, or W spaces.

Table 4-1 Analysis results based on average spectrum auction pieces of block A,B, and C.

\begin{tabular}{ccc}
\hline Station \# & Earth Station Name & \$/MHz-POP \\
\hline $\mathbf{1}$ & Wallops Island, VA & 0.03 \\
\hline $\mathbf{2}$ & Fairbanks, AK & 0.14 \\
\hline $\mathbf{3}$ & Suitland, MD & 0.88 \\
\hline $\mathbf{4}$ & Miami, FL & 0.54 \\
\hline $\mathbf{5}$ & Ford Island, Pearl Harbor HI & 0.18 \\
\hline $\mathbf{6}$ & Sioux Falls, SD & 0.09 \\
\hline $\mathbf{7}$ & Elmendorf Air Force Base, AK & 0.14 \\
\hline $\mathbf{8}$ & Anderson Air Force Base, GU & 0.00 \\
\hline $\mathbf{9}$ & Monterey, CA & 0.44 \\
\hline $\mathbf{1 0}$ & Stennis Space Center, MI & 0.41 \\
\hline $\mathbf{1 1}$ & Twenty-Nine-Palms, CA & 0.60 \\
\hline $\mathbf{1 2}$ & Yuma, AZ & 0.60 \\
\hline $\mathbf{1 3}$ & Cincinnati, OH & 0.50 \\
\hline $\mathbf{1 4}$ & Rock Island, IL & 0.12 \\
\hline $\mathbf{1 5}$ & St. Louis, MO & 0.33 \\
\hline $\mathbf{1 1 6}$ & Vicksburg, MS & 0.15 \\
\hline $\mathbf{1 7}$ & Omaha, NE & 0.32 \\
\hline $\mathbf{1 8}$ & Sacramento, CA & 0.19 \\
\hline
\end{tabular}

These \$/MHz-POP numbers are the final output of this analysis, and the input to the simulation model.

\subsubsection{Black Space Area}

The summary of black space analysis is listed in Appendix B (Table B1). The total B space area worth $\$ 193$ million. Some black spaces are very small in area and impacted relatively large populations; the value, then, depends more on the population density more than on the size of the geographic area. 
According to our definition, the black space boundary occurs when the PU receiver will accept more than $20 \mathrm{dBm}$ as additional aggregated interference above the noise floor of that receiver. So, in some earth-stations, the black space is very valuable and may be worth sharing.

"Anderson Air Force Base, GU" earth-station is not included in the table, because it is on an unpopulated island. Thus, effect of the exclusion zone is insignificant at this location.

\subsubsection{Gray Space Area}

The summary of gray space analysis is listed in Appendix B (Table B2). The total G space area is worth $\$ 52$ million. The percentage of total area impacted at both B and G space are similar. However, the percentage of total populated impacted at $\mathrm{G}$ space is almost half the B space case.

\subsubsection{White Space Area}

This information listed at Table 4-2 is very critical and clearly shows the benefits of sharing the band with the PU. Where USs share the band, and aggregated interference falls below the noise floor of the PU (W space sharing), that will give $\$ 2.3$ billion worth of spectrum.

This will incur a lower enforcement cost compared to G or B space sharing. It is most likely that the enforcement cost at this $\mathrm{W}$ space will be less than the benefits. That gives more incentive to share the band at this space type.

Table 4-2 Benefits evaluation suammary of B, G, and W Spaces

\begin{tabular}{ccccc}
\hline & Black & Gray & Black + Gray & White \\
\hline Total Area Impacted (\%) & $0.70 \%$ & $0.87 \%$ & $1.56 \%$ & $98 \%$ \\
\hline Total Population Impacted (\%) & $5.83 \%$ & $2.80 \%$ & $8.63 \%$ & $91 \%$ \\
\hline Total Value (\$ million) & 193 & 52 & 245 & 2,327 \\
\hline
\end{tabular}




\subsubsection{Relocation of Earth-stations}

In this section, we assess the benefits of relocating earth-stations that cause the most impacted percentage on sharing utilization. The following Table 4-3 lists the stations inputs. We can see that the first five earth-stations account for $90 \%$ of the benefits gained from sharing. In addition, the first three earth-stations account for $79 \%$ of the benefits.

The idea here is to relocate the earth-stations with the highest sharing benefits to another area with less population. If we assume the total cost (including the cost of the impacted population in the new location) of relocating an earth-station would be $\$ 3$ million, then the value of the spectrum based on the affected population exceeds the cost of relocation for the first eight earth-stations. This suggests that there may be a social benefit to their relocation.

Table 4-3 Relocation Benefits of the 18 earth-station, based on $B+G$ values.

\begin{tabular}{|c|c|c|c|c|c|}
\hline \multirow{2}{*}{$\begin{array}{c}\text { Station } \\
\quad \#\end{array}$} & \multirow{2}{*}{ Earth Station Name } & \multirow{2}{*}{ Value (\$) } & \multirow{2}{*}{$\begin{array}{c}\text { Order } \\
\#\end{array}$} & \multicolumn{2}{|c|}{ Grouping } \\
\hline & & & & Method \#1 & Method \#2 \\
\hline 3 & Suitland, MD & $134,976,113$ & 1 & \multirow{5}{*}{$90 \%$} & \multirow{3}{*}{$79 \%$} \\
\hline 4 & Miami, FL & $34,320,545$ & 2 & & \\
\hline 11 & Twenty-Nine-Palms, CA & $23,971,324$ & 3 & & \\
\hline 13 & Cincinnati, $\mathrm{OH}$ & $13,797,514$ & 4 & & \multirow{15}{*}{$21 \%$} \\
\hline 9 & Monterey, CA & $13,316,321$ & 5 & & \\
\hline 10 & Stennis Space Center, MI & $9,530,951$ & 6 & \multirow{13}{*}{$10.00 \%$} & \\
\hline 18 & Sacramento, CA & $3,434,079$ & 7 & & \\
\hline 15 & St. Louis, MO & $3,101,571$ & 8 & & \\
\hline 5 & Ford Island, Pearl Harbor HI & $2,727,747$ & 9 & & \\
\hline 12 & Yuma, AZ & $1,770,843$ & 10 & & \\
\hline 16 & Vicksburg, MS & $1,174,559$ & 11 & & \\
\hline 7 & Elmendorf Air Force Base, AK & 747,481 & 12 & & \\
\hline 14 & Rock Island, IL & 631,456 & 13 & & \\
\hline 1 & Wallops Island, VA & 466,638 & 14 & & \\
\hline 17 & Omaha, NE & 417,872 & 15 & & \\
\hline 6 & Sioux Falls, SD & 398,119 & 16 & & \\
\hline 2 & Fairbanks, AK & 139,170 & 17 & & \\
\hline 8 & Anderson Air Force Base, GU & - & 18 & & \\
\hline
\end{tabular}




\subsection{Spectrum Sharing in 3.5GHz band}

The FCC proposes specific rules for a "Citizens Broadband Radio Service" in the $3.5 \mathrm{GHz}$ Band that would make the $3.5 \mathrm{GHz}$ sharing regime, originally described by the PCAST report, a reality. In December 2012, the FCC published the first "Notice of Proposed Rulemaking", which was followed by a revised proposed framework described in the "Licensing Public Notice" [16]. In April 2014, the FCC issued the most recent notice (called "Further Notice of Proposed Rulemaking"), which was developed based on responses to a series of prior proposals and workshops [17].

Originally, the NTIA in the Fast Track report recommended reallocating 100 megahertz of the 3550-3650 MHz band for wireless broadband use within five years (Fast Track report published in October 2010) [5]. To get more information about PUs and SUs discussion, please refer to [9].

\subsubsection{Simulation Setting}

As mentioned in a recent report from the FCC [17], many services/technologies have been proposed to share the band with PUs. The most common feature is that it is expected to be "small cell" topology(s). Even the PCAST report goes in this direction, recommending small cells in $3.5 \mathrm{GHz}$ band [4]. In this paper, we will consider the following two types of technologies to demonstrate our model:

\section{LTE network}

2. Femtocells and WiFi

All the PU technical specifications used in this model are based on the NTIA analysis [5]. Some necessary information is missing; however, we have made certain assumptions as detailed below. Table 4-4 summarizes the specifications about the shipborne radars. 
Table 4-4 Specifications of shipborne radars.

\begin{tabular}{lccccc}
\hline & $\begin{array}{c}\text { Antenna } \\
\text { Gain } \\
(\mathbf{d B i})\end{array}$ & $\begin{array}{c}\text { Antenna } \\
\text { Losses } \\
(\mathbf{d B})\end{array}$ & $\begin{array}{c}\text { Antenna } \\
\text { Height } \\
(\mathbf{m})\end{array}$ & $\begin{array}{c}\text { Gboundary }(\mathbf{d B m}) \\
\text { Interference } \\
\text { Threshold }\}\end{array}$ & $\begin{array}{c}\text { Bboundary } \\
(\mathbf{d B m}) \\
\text { [Gboundary }+\mathbf{1 0}\}\end{array}$ \\
\hline Shipborne 1 & 32 & 2 & 50 & -114 & -104 \\
\hline Shipborne 2 & 47 & 2 & 30 & -101 & -91 \\
\hline Shipborne 3 & 41.8 & 3.4 & 30 & -100 & -90 \\
\hline Shipborne 4 & 38.9 & 2 & 30 & -110 & -100 \\
\hline Shipborne 5 & 43.3 & 2 & 30 & -110 & -100 \\
\hline
\end{tabular}

Based on Census Bureau data [18], the average population density of the coastal shoreline counties (excluding Alaska) is 172 person per $\mathrm{km}^{2}$. The density in the US as a whole averages 40 people per $\mathrm{km}^{2}$. To capture those data in the model:

- Inner area density ( 0 to $50 \mathrm{~km}) \quad=172$ person per $\mathrm{km}^{2}$

- Outer area density (50 to $100 \mathrm{~km})=40$ person per $\mathrm{km}^{2}$

\subsubsection{Spectrum Sharing Benefits Evaluation}

\subsubsection{LTE Scenario}

Here, a full LTE network is considered (both LTE base stations and LTE-UE), although, this scenario is not consistent with the direction of having only small cell technologies in this band. However, we want to examine all possible scenario in this research.

The relation of LTE base stations to each other is completely independent. Both LTE base stations and LTE-UE are randomly and uniformly distributed over the simulated area, since we examine aggregated interference effect to the PU antenna, not the performance of LTE network; see Table 4-5. From Appendix C (Table C1), we can notice the following: 
- Shipborne 1 still has the largest radiuses.

- Once the SUs active factor changes over $0.05 \%, 0.1 \%$, and $0.5 \%$; the percentage of change in radiuses is different from radar to another. That due to the different characteristics of each one of these five radars.

- In some cases (e.g. the terrain type of "large city" at shipborne 2 and 3), the B and $\mathrm{G}$ radius is very small.

- NTIA assumes that the shipborne radar will be at a distance of $10 \mathrm{~km}$ from the coast line.

- If we consider that in our analysis, we will end up with some cases where the $\mathrm{B}$ and $\mathrm{G}$ radius is zero. (we considered the shipborne radars on the coast line as the worst case scenario in our model)

- Since shipborne 1 causes the largest exclusion zones among the five radars, Table 4-6 summarize the benefits of $\mathrm{W}, \mathrm{G}$, and B spaces over the US.

Table 4-5 LTE network topology

\begin{tabular}{lc}
\hline \multicolumn{1}{c}{ Terrain Type } & Ratio \\
\hline Small and large city areas & $\begin{array}{c}\{1 \text { to } 22\} \\
\text { One LTE base station for each } 22 \text { active LTE-UE }\end{array}$ \\
\hline $\begin{array}{l}\{1 \text { to } 6\} \\
\text { Suburban and open areas }\end{array}$ & One LTE base station for each 6 active LTE-UE \\
\hline $\begin{array}{l}\text { All the LTE base station transmit at fixed power }=46 \mathrm{dBm} . \\
\text { At the NTIA-CSMAC analysis [15]; } 1 \text { to } 18 \text { ratio had been used over all different terrain } \\
\text { types. }\end{array}$
\end{tabular}


Table 4-6: W, G, and B space value for Shipborne 1 in LTE Scenario

\begin{tabular}{|c|c|c|c|c|c|c|}
\hline \multirow{2}{*}{\multicolumn{2}{|c|}{ (\$ Million) }} & \multicolumn{4}{|c|}{ Terrain Type } & \multirow{2}{*}{$\begin{array}{l}\text { Average } \\
\text { (25\% each) }\end{array}$} \\
\hline & & Open & Suburban & Small City & Large City & \\
\hline \multirow{4}{*}{$\begin{array}{l}\text { Space } \\
\text { Type }\end{array}$} & Black & 664 & 608 & 443 & 437 & 538 \\
\hline & Gray & 60 & 76 & 162 & 131 & 107 \\
\hline & Black + Gray & 723 & 684 & 606 & 568 & 645 \\
\hline & White & 2,364 & 2,403 & 2,482 & 2,519 & 2,442 \\
\hline
\end{tabular}

\subsubsection{Femtocells and WiFi Scenario}

In this scenario, it is assumed both the transmitter and receiver have the same probability distribution function (PDF). The PDF is same as LTE-UE in urban area, where the transmitted power is relatively less since the distance between the transmitter and receiver is short. We ignore the factor or different type of traffic been carried over this scenario, we simulate a PDF of transmitted power $(\mathrm{dBm})$ regardless if it is Femtocells or WiFi users.

The SU density has been examined over three cases (Active factor $=0.5 \%, 0.1 \%$, and $0.05 \%$ ) to study the sensitivity of that over the result. From Appendix C (Table C2)Table, we can notice the following:

- Since these type of technologies are small cell, there is huge reduction in G and B radiuses. Which gives advantage to small cell technologies over LTE to share this band, which increase the sharing utilization.

- The majority of the cases list in this Table $\mathrm{C} 2$ show that, in large cities, the radii will be minimal. That is an interesting finding since the highest SUs density located in large cities. 
Table 4-7: W, G, and B space value for Shipborne 1 in Femtocells and WiFi Scenario

\begin{tabular}{cccccccc}
\hline & & \multicolumn{5}{c}{ Terrain Type } & \multirow{2}{*}{$\begin{array}{c}\text { Average } \\
\text { (25\% each) }\end{array}$} \\
\cline { 2 - 6 } & Opillion) & Open & Suburban & Small City & Large City & \\
\hline & Black & 662 & 186 & 13 & 14 & 219 \\
\cline { 2 - 6 } $\begin{array}{c}\text { Space } \\
\text { Type }\end{array}$ & Gray & 50 & 305 & 42 & 47 & 111 \\
\cline { 2 - 6 } & Black + Gray & 712 & 491 & 55 & 61 & 330 \\
\cline { 2 - 6 } & White & 2,376 & 2,596 & 3,033 & 3,026 & 2,758 \\
\hline
\end{tabular}

\subsection{Conclusion}

Spectrum sharing has gone from an idea to a serious policy focus in one decade. As with many new and possibly disruptive technologies, spectrum sharing poses challenges for stakeholders, which include incumbents, regulators and entrants. Incumbents have made investments that are often sunk costs to utilize the spectrum for which they have a license. Over the course of nearly a century, regulators have developed regulations that have been tested in the field and in courts that is based on the "command and control" licensing regime. Entrants are being pressed by the marketplace and enabled by new technologies to develop new approaches to exploiting the resource that is RF spectrum. Thus, it is no wonder that the specter of spectrum sharing has political, economic, technical and legal implications. In this paper, we have sought to provide some specific insight into some techno-economic aspects of cooperative spectrum sharing in two particular scenarios.

The main goal of his paper is to develop a relationship between enforcement methodologies and benefits of spectrum sharing through sharing between government and commercial users. In particular, we sought to shed light on the relationship between common enforcement strategies and their economic consequences in terms of lost value for two bands that are actively being considered for government-commercial sharing by the NTIA. While the results reported here are specific to these particular sharing scenarios, the approach (and some of the lessons) may be generalizable to other bands and other sharing scenarios as well. 
One of the aims of this research is to develop some recommendations for principal stakeholders to facilitate spectrum sharing. In particular, we develop some recommendations for the sharing enforcement authority/agency that are drawn from the simulation model. This analysis is valuable because it will help regulators/governments prepare for possible future scenarios in solving wireless capacity crunch. In addition, it can give government users (Federal and non-Federal) more insight into expected future sharing. It is also of value to commercial users and operators in that they can use the results of this work to make more informed decisions of the economic benefits of different spectrum sharing market and opportunities.

\section{References}

[1] FCC, "The Benefits of Additional Spectrum," Federal Communications Commission , 2010.

[2] Cisco, "Cisco Visual Networking Index : Global Mobile Data Traffic Forecast Update , 2012 - 2017," 2013.

[3] FCC, "Connecting America: The National Broadband Plan," Federal Communications Commission , 2010.

[4] PCAST, "REPORT TO THE PRESIDENT REALIZING THE FULL POTENTIAL OF GOVERNMENT-HELD SPECTRUM TO SPUR ECONOMIC GROWTH,” 2012.

[5] NTIA, "An Assessment of the Near-Term Viability of Accommodating Wireless Broadband Systems in the 1675-1710 MHz, 1755-1780 MHz, 3500-3650 MHz, and 4200$4220 \mathrm{MHz}, 4380-4400$ MHz Bands," 2010.

[6] NTIA, "Plan and Timetable to Make Available 500 Megahertz of Spectrum for Wireless Broadband," no. October, 2010.

[7] W. Webb, Understanding Weightless: Technology, Equipment, and Network Deployment for M2M Communications in White Space. Cambridge University Press, 2012, p. 220.

[8] M. B. H. Weiss, M. Altamimi, and M. Mchenry, "Enforcement and Spectrum Sharing : A Case Study of the 1695-1710 MHz Band," 2013.

[9] M. Altamimi, M. B. H. Weiss, and M. McHenry, "Enforcement and Spectrum Sharing: Case Studies of Federal-Commercial Sharing," SSRN Electron. J., 2013. 
[10] J. P. de Vries and K. a. Sieh, "Reception-oriented radio rights: Increasing the value of wireless by explicitly defining and delegating radio operating rights," Telecomm. Policy, vol. 36, no. 7, pp. 522-530, Aug. 2012.

[11] J. P. de Vries, "How I Learned to Stop Worrying and Love Interference: Using WellDefined Radio Rights to Boost Concurrent Operation," SSRN Electron. J., 2010.

[12] M. B. H. Weiss, W. H. Lehr, L. Cui, and M. Altamaimi, "Enforcement in Dynamic Spectrum Access Systems.” Telecommunications Policy Research Conference, 22-Sep2012.

[13] R. Clarke, "Expanding Mobile Wireless Capacity: The Challenges Presented by Technology and Economics," Available SSRN 2197416, 2013.

[14] ITU, "Recommendation ITU-R F.1245-1," 2000.

[15] M. Meteorological-satellite, "CSMAC Working Group 1 ( WG-1 ) Report 18 June 2013 Overview," 2013.

[16] FCC, "NOTICE OF PROPOSED RULEMAKING AND ORDER (FCC 12-148)."

[17] FCC, "FURTHER NOTICE OF PROPOSED RULEMAKING."

[18] U. C. Bureau, “detail_page_visual-standard-U.S. Census Bureau." 


\section{Appendix (A): Specifications of MetSat earth-stations}

Table A1: The specification of the MetSat 18 earth-stations.

\begin{tabular}{ccccc}
\hline & Larth Station Name & Latitude & Longitude & $\begin{array}{c}\text { Station } \\
\text { Type }\end{array}$ \\
\hline $\mathbf{1}$ & Wallops Island, VA & $375645 \mathrm{~N}$ & $0752745 \mathrm{~W}$ & POES/GOES \\
\hline $\mathbf{2}$ & Fairbanks, AK & $644814 \mathrm{~N}$ & $1475234 \mathrm{~W}$ & POES/GOES \\
\hline $\mathbf{3}$ & Suitland, MD & $385107 \mathrm{~N}$ & $0765613 \mathrm{~W}$ & POES/GOES \\
\hline $\mathbf{4}$ & Miami, FL & $254700 \mathrm{~N}$ & $0801900 \mathrm{~W}$ & POES/GOES \\
\hline $\mathbf{5}$ & Ford Island, Pearl Harbor HI & $212212 \mathrm{~N}$ & $1575744 \mathrm{~W}$ & POES/GOES \\
\hline $\mathbf{6}$ & Sioux Falls, SD & $434409 \mathrm{~N}$ & $0963733 \mathrm{~W}$ & POES/GOES \\
\hline $\mathbf{7}$ & Elmendorf Air Force Base, AK & $610859 \mathrm{~N}$ & $1492812 \mathrm{~W}$ & POES/GOES \\
\hline $\mathbf{8}$ & Anderson Air Force Base, GU & $133452 \mathrm{~N}$ & $1445528 \mathrm{E}$ & POES/GOES \\
\hline $\mathbf{9}$ & Monterey, CA & $363600 \mathrm{~N}$ & $1215400 \mathrm{~W}$ & POES/GOES \\
\hline $\mathbf{1 0}$ & Stennis Space Center, MI & $302359 \mathrm{~N}$ & $0893559 \mathrm{~W}$ & POES/GOES \\
\hline $\mathbf{1 1}$ & Twenty-Nine-Palms, CA & $341746 \mathrm{~N}$ & $1160944 \mathrm{~W}$ & POES/GOES \\
\hline $\mathbf{1 2}$ & Yuma, AZ & $323924 \mathrm{~N}$ & $1143622 \mathrm{~W}$ & POES/GOES \\
\hline $\mathbf{1 3}$ & Cincinnati, OH & $390608 \mathrm{~N}$ & $0843036 \mathrm{~W}$ & GOES \\
\hline $\mathbf{1 4}$ & Rock Island, IL & $413104 \mathrm{~N}$ & $0903346 \mathrm{~W}$ & GOES \\
\hline $\mathbf{1 5}$ & St. Louis, MO & $383526 \mathrm{~N}$ & $0901225 \mathrm{~W}$ & GOES \\
\hline $\mathbf{1 6}$ & Vicksburg, MS & $322123 \mathrm{~N}$ & $0905129 \mathrm{~W}$ & GOES \\
\hline $\mathbf{1 7}$ & Omaha, NE & $412056 \mathrm{~N}$ & $0957534 \mathrm{~W}$ & GOES \\
\hline $\mathbf{1 8}$ & Sacramento, CA & $383550 \mathrm{~N}$ & $1213234 \mathrm{~W}$ & GOES \\
\hline & & & & \\
\hline
\end{tabular}


TableA2: Detailed specifications for each MetSat 18 earth-station.

\begin{tabular}{|c|c|c|c|c|c|}
\hline $\begin{array}{c}\text { Earth } \\
\text { Station } \\
\text { Number }\end{array}$ & $\begin{array}{c}\text { POP within } \\
\text { Radius=100 km } \\
\text { (Population) }\end{array}$ & $\begin{array}{c}\text { Minimum } \\
\text { Elevation Angle } \\
\text { (Degree) }\end{array}$ & $\begin{array}{c}\text { Antenna } \\
\text { Gain } \\
\text { (dBi) }\end{array}$ & $\begin{array}{c}\text { Antenna } \\
\text { Height } \\
\text { (m) }\end{array}$ & $\begin{array}{c}\text { Interference } \\
\text { Protection } \\
\text { Threshold } \\
\text { (dBm) }\end{array}$ \\
\hline 1 & 553,281 & 14 & 43.1 & 17 & 120.6 \\
\hline 2 & 98,102 & 14 & 43.1 & 17 & 120.6 \\
\hline 3 & $8,537,701$ & 5 & 29.5 & 86.8 & 120.9 \\
\hline 4 & $5,075,122$ & 5 & 29 & 33 & 124.1 \\
\hline 5 & 955,959 & 5 & 29 & 33 & 120.9 \\
\hline 6 & 408,398 & 27.7 & 31 & 14.5 & 121.6 \\
\hline 7 & 401,952 & 5 & 29 & 33 & 120.9 \\
\hline 8 & 0 & 5 & 29 & 33 & 120.9 \\
\hline 9 & $2,574,415$ & 5 & 29 & 33 & 120.9 \\
\hline 10 & $1,780,419$ & 5 & 29 & 33 & 120.9 \\
\hline 11 & $2,710,745$ & 5 & 29 & 33 & 120.9 \\
\hline 12 & 334,248 & 5 & 29 & 33 & 120.9 \\
\hline 13 & $3,376,536$ & 43.9 & 39 & 200 & 122.5 \\
\hline 14 & 974,045 & 24.4 & 39.6 & 25 & 122.5 \\
\hline 15 & $2,999,809$ & 42.6 & 36.7 & 20 & 122.5 \\
\hline 16 & 746,133 & 48.6 & 36.7 & 20 & 122.5 \\
\hline 17 & $1,327,903$ & 28 & 36.7 & 20 & 122.5 \\
\hline 18 & $4,669,749$ & 43.2 & 36.7 & 20 & 122.5 \\
\hline
\end{tabular}




\section{Appendix (B): 1.7GHz Band Analysis}

Table B1: Benefits evaluation sammary of B Spaces

\begin{tabular}{|c|c|c|c|c|}
\hline \multirow{2}{*}{ station \# } & \multicolumn{4}{|c|}{ Black Space Analysis } \\
\hline & $\begin{array}{c}\text { Radius } \\
(\mathrm{km})\end{array}$ & Population Affected & $\begin{array}{c}\text { Population } \\
\text { Impacted (\%) }\end{array}$ & Value (\$) \\
\hline 1 & 56.73 & 175,304 & $0.06 \%$ & 187,945 \\
\hline 2 & 3.55 & 7,894 & $0.00 \%$ & 19,223 \\
\hline 3 & 78.55 & $7,707,479$ & $2.50 \%$ & $123,248,661$ \\
\hline 4 & 40.12 & $3,310,138$ & $1.07 \%$ & $23,856,598$ \\
\hline 5 & 29.52 & 913,032 & $0.30 \%$ & $2,612,780$ \\
\hline 6 & 5.41 & 1,579 & $0.00 \%$ & 2,261 \\
\hline 7 & 25.54 & 268,289 & $0.09 \%$ & 579,678 \\
\hline 8 & 15.48 & - & - & - \\
\hline 9 & 63.53 & 775,494 & $0.25 \%$ & $4,333,835$ \\
\hline 10 & 83.00 & $1,015,651$ & $0.33 \%$ & $6,000,135$ \\
\hline 11 & 98.49 & $2,610,050$ & $0.85 \%$ & $23,402,738$ \\
\hline 12 & 13.81 & 114,054 & $0.04 \%$ & $1,040,131$ \\
\hline 13 & 21.65 & $1,036,004$ & $0.34 \%$ & $7,473,844$ \\
\hline 14 & 2.20 & 14,867 & $0.00 \%$ & 27,861 \\
\hline 15 & 0.99 & 26,937 & $0.01 \%$ & 146,598 \\
\hline 16 & 4.28 & 7,128 & $0.00 \%$ & 17,466 \\
\hline 17 & 1.27 & 2,819 & $0.00 \%$ & 9,453 \\
\hline 18 & 0.82 & 19,001 & $0.01 \%$ & 60,152 \\
\hline \multicolumn{4}{|c|}{ Total Area Impacted (\%) } & $0.70 \%$ \\
\hline \multicolumn{4}{|c|}{ Total Population Impacted (\%) } & $5.83 \%$ \\
\hline \multicolumn{4}{|c|}{ Total Value (\$) } & $193,019,360$ \\
\hline
\end{tabular}


Table B2: Benefits evaluation summary of G Spaces

\begin{tabular}{|c|c|c|c|c|}
\hline \multirow[b]{2}{*}{ station \# } & \multicolumn{4}{|c|}{ Gray Space Analysis } \\
\hline & $\begin{array}{l}\text { Radius } \\
(\mathrm{km})\end{array}$ & Population Affected & $\begin{array}{c}\text { Population } \\
\text { Impacted (\%) }\end{array}$ & Value \\
\hline 1 & 92.20 & 259,949 & $0.08 \%$ & 278,693 \\
\hline 2 & 12.75 & 49,258 & $0.02 \%$ & 119,948 \\
\hline 3 & 97.62 & 733,388 & $0.24 \%$ & $11,727,452$ \\
\hline 4 & 90.51 & $1,451,888$ & $0.47 \%$ & $10,463,947$ \\
\hline 5 & 39.48 & 40,175 & $0.01 \%$ & 114,967 \\
\hline 6 & 62.44 & 276,428 & $0.09 \%$ & 395,858 \\
\hline 7 & 60.37 & 77,663 & $0.03 \%$ & 167,802 \\
\hline 8 & 78.67 & - & - & - \\
\hline 9 & 91.21 & $1,607,321$ & $0.52 \%$ & $8,982,486$ \\
\hline 10 & 95.10 & 597,666 & $0.19 \%$ & $3,530,816$ \\
\hline 11 & 99.70 & 63,413 & $0.02 \%$ & 568,586 \\
\hline 12 & 36.44 & 80,125 & $0.03 \%$ & 730,711 \\
\hline 13 & 46.20 & 876,570 & $0.28 \%$ & $6,323,670$ \\
\hline 14 & 32.30 & 322,087 & $0.10 \%$ & 603,595 \\
\hline 15 & 13.44 & 542,969 & $0.18 \%$ & $2,954,973$ \\
\hline 16 & 70.57 & 472,218 & $0.15 \%$ & $1,157,093$ \\
\hline 17 & 10.19 & 121,799 & $0.04 \%$ & 408,420 \\
\hline 18 & 21.39 & $1,065,758$ & $0.35 \%$ & $3,373,926$ \\
\hline \multicolumn{4}{|c|}{ Total Area Impacted (\%) } & $0.87 \%$ \\
\hline \multicolumn{4}{|c|}{ Total Population Impacted (\%) } & $2.80 \%$ \\
\hline \multicolumn{4}{|c|}{ Total Value (\$) } & $51,902,943$ \\
\hline
\end{tabular}




\section{Appendix (C): 3.5GHz Band Analysis}

Table C1: Black and Gray space radius for LTE scenario

\begin{tabular}{|c|c|c|c|c|c|c|c|c|}
\hline & \multicolumn{4}{|c|}{ Black Space (km) } & \multicolumn{4}{|c|}{ Gray Space (km) } \\
\hline & \multicolumn{8}{|c|}{ SUs Active Factor $=0.5 \%$} \\
\hline & ฮี & 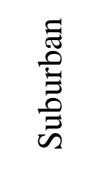 & 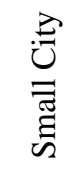 & 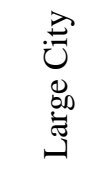 & $\begin{array}{l}\bar{\Xi} \\
\text { ठे. }\end{array}$ & 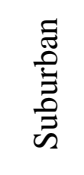 & 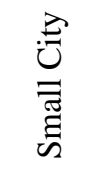 & 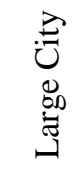 \\
\hline Shipborne 1 & 91.5 & 87.4 & 57.9 & 54.9 & 99.2 & 94.5 & 84.3 & 83.2 \\
\hline Shipborne 2 & 67.3 & 42.4 & 24.7 & 25.9 & 93.5 & 60.8 & 37.9 & 38.5 \\
\hline Shipborne 3 & 70.1 & 43.3 & 26.5 & 25.6 & 94.5 & 60.9 & 39.6 & 38.5 \\
\hline Shipborne 4 & 88.2 & 66.6 & 40.2 & 39.7 & 97.7 & 85.6 & 55.5 & 51.8 \\
\hline \multirow[t]{3}{*}{ Shipborne 5} & 67.7 & 56.7 & 38.4 & 38.4 & 97.3 & 84.2 & 51.0 & 50.1 \\
\hline & \multicolumn{8}{|c|}{ SUs Active Factor $=0.1 \%$} \\
\hline & ठี & 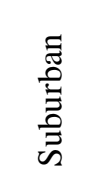 & 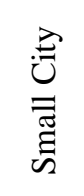 & 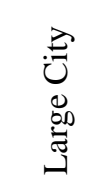 & $\begin{array}{l}\bar{\Xi} \\
\text { ठั. }\end{array}$ & 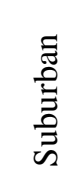 & 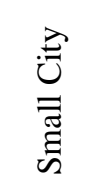 & 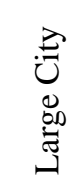 \\
\hline Shipborne 1 & 72.0 & 52.3 & 36.8 & 36.3 & 93.3 & 79.4 & 51.3 & 47.2 \\
\hline Shipborne 2 & 41.9 & 19.0 & 2.0 & 2.8 & 66.2 & 40.9 & 12.2 & 13.6 \\
\hline Shipborne 3 & 34.5 & 24.8 & 3.4 & 2.5 & 69.5 & 37.8 & 15.2 & 17.5 \\
\hline Shipborne 4 & 61.7 & 36.7 & 18.2 & 13.3 & 89.3 & 55.3 & 34.5 & 32.7 \\
\hline \multirow[t]{3}{*}{ Shipborne 5} & 69.0 & 34.1 & 12.3 & 17.7 & 87.6 & 50.0 & 32.1 & 33.7 \\
\hline & \multicolumn{8}{|c|}{ SUs Active Factor $=0.05 \%$} \\
\hline & $\begin{array}{l}\overline{0} \\
\text { ठั. }\end{array}$ & 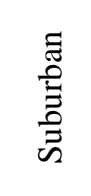 & 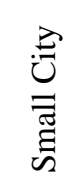 & 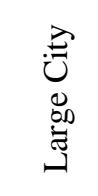 & $\begin{array}{l}\bar{\Xi} \\
\text { ठั. }\end{array}$ & 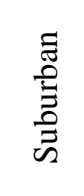 & 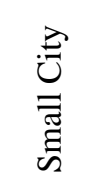 & 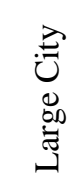 \\
\hline Shipborne 1 & 63.9 & 46.7 & 26.4 & 26.2 & 93.0 & 65.9 & 42.5 & 39.3 \\
\hline Shipborne 2 & 31.6 & 8.7 & 1.3 & 1.0 & 53.7 & 33.4 & 9.1 & 5.2 \\
\hline Shipborne 3 & 35.3 & 8.6 & 0.9 & 1.4 & 57.3 & 28.7 & 5.7 & 8.0 \\
\hline Shipborne 4 & 52.0 & 22.2 & 7.3 & 4.6 & 78.3 & 44.9 & 22.5 & 26.0 \\
\hline Shipborne 5 & 51.2 & 25.0 & 4.6 & 5.3 & 75.6 & 46.8 & 21.0 & 19.9 \\
\hline
\end{tabular}


Table C2: Black and Gray space radius for Femtocell-WiFi scenario

\begin{tabular}{|c|c|c|c|c|c|c|c|c|}
\hline & \multicolumn{4}{|c|}{ Black Space $(\mathbf{k m})$} & \multicolumn{4}{|c|}{ Gray Space $(\mathbf{k m})$} \\
\hline & \multicolumn{8}{|c|}{ SUs Active Factor $=0.5 \%$} \\
\hline & $\begin{array}{l}\text { ळँ } \\
\text { ठे }\end{array}$ & 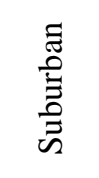 & 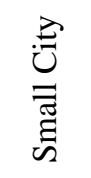 & 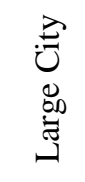 & ठี & 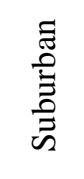 & 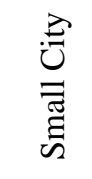 & 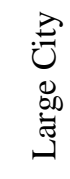 \\
\hline Shipborne 1 & 93.8 & 47.1 & 15.1 & 14.5 & 97.8 & 77.2 & 41.1 & 40.4 \\
\hline Shipborne 2 & 48.3 & 1.7 & 0.0 & 0.0 & 75.5 & 23.7 & 0.8 & 1.0 \\
\hline Shipborne 3 & 48.3 & 1.9 & 0.0 & 0.0 & 77.5 & 25.2 & 0.9 & 1.0 \\
\hline Shipborne 4 & 79.4 & 26.0 & 1.1 & 1.0 & 92.9 & 46.4 & 13.2 & 13.6 \\
\hline \multirow[t]{3}{*}{ Shipborne 5} & 77.3 & 23.2 & 1.2 & 1.0 & 92.3 & 44.2 & 10.4 & 11.1 \\
\hline & \multicolumn{8}{|c|}{ SUs Active Factor $=0.1 \%$} \\
\hline & $\begin{array}{l}\text { ठี } \\
\text { ठี }\end{array}$ & $\begin{array}{l}\overline{0} \\
\stackrel{0}{\Xi} \\
\vdots \\
\bar{\Xi}\end{array}$ & 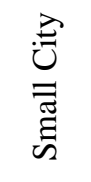 & 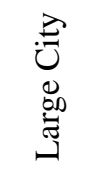 & ई̃ & 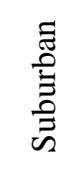 & 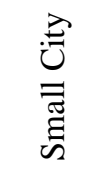 & 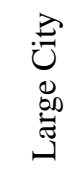 \\
\hline Shipborne 1 & 71.5 & 15.4 & 1.1 & 1.2 & 89.2 & 40.8 & 4.5 & 5.1 \\
\hline Shipborne 2 & 16.4 & 0.0 & 0.0 & 0.0 & 41.9 & 2.0 & 1.8 & 1.8 \\
\hline Shipborne 3 & 16.5 & 0.0 & 0.0 & 0.0 & 42.4 & 1.8 & 1.7 & 1.7 \\
\hline Shipborne 4 & 43.6 & 2.4 & 0.0 & 0.0 & 66.4 & 13.0 & 1.8 & 2.1 \\
\hline \multirow[t]{3}{*}{ Shipborne 5} & 42.4 & 1.9 & 0.0 & 0.0 & 63.8 & 10.9 & 1.8 & 1.8 \\
\hline & \multicolumn{8}{|c|}{ SUs Active Factor $=0.05 \%$} \\
\hline & ठี & 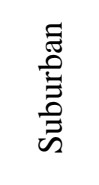 & 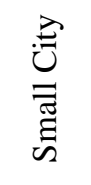 & 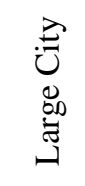 & ठี & 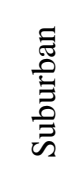 & 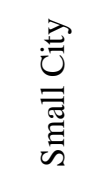 & 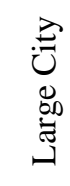 \\
\hline Shipborne 1 & 52.0 & 3.4 & 0.0 & 0.0 & 81.2 & 27.2 & 2.5 & 2.5 \\
\hline Shipborne 2 & 4.6 & 0.0 & 0.0 & 0.0 & 23.7 & 2.8 & 2.2 & 2.8 \\
\hline Shipborne 3 & 4.7 & 0.0 & 0.0 & 0.0 & 26.8 & 2.5 & 2.7 & 2.7 \\
\hline Shipborne 4 & 29.8 & 0.0 & 0.0 & 0.0 & 51.5 & 2.8 & 2.3 & 2.4 \\
\hline Shipborne 5 & 28.1 & 0.0 & 0.0 & 0.0 & 50.7 & 3.7 & 2.7 & 2.0 \\
\hline
\end{tabular}

